Cite this: Dalton Trans., 2014, 43, 8679

Received 21st February 2014, Accepted 15th April 2014

DOI: $10.1039 / c 4 d t 00555 d$

www.rsc.org/dalton

\section{A study of the optical properties of metal-doped polyoxotitanium cages and the relationship to metal-doped titania $\uparrow$}

\author{
Yaokang LV, ${ }^{\mathrm{a}, \mathrm{b}}$ Jun Cheng, ${ }^{\text {c }}$ Peter D. Matthews, ${ }^{a}$ Juan Pedro Holgado, ${ }^{\mathrm{d}}$ \\ Janina Willkomm, ${ }^{a}$ Michal Leskes, ${ }^{a}$ Alexander Steiner, ${ }^{e}$ Dieter Fenske, ${ }^{f}$ \\ Timothy C. King, ${ }^{a}$ Paul T. Wood, ${ }^{a}$ Lihua Gan, ${ }^{\star b}$ Richard M. Lambert ${ }^{a, d}$ and \\ Dominic S. Wright*a
}

\begin{abstract}
To what extent the presence of transition metal ions can affect the optical properties of structurally welldefined, metal-doped polyoxotitanium (POT) cages is a key question in respect to how closely these species model technologically important metal-doped $\mathrm{TiO}_{2}$. This also has direct implications to the potential applications of these organically-soluble inorganic cages as photocatalytic redox systems in chemical transformations. Measurement of the band gaps of the series of closely related polyoxotitanium cages $\left[\mathrm{MnTi}_{14}(\mathrm{OEt})_{28} \mathrm{O}_{14}(\mathrm{OH})_{2}\right]$ (1), $\left[\mathrm{FeTi}_{14}(\mathrm{OEt})_{28} \mathrm{O}_{14}(\mathrm{OH})_{2}\right]$ (2) and $\left[\mathrm{GaTi}_{14}(\mathrm{OEt})_{28} \mathrm{O}_{15}(\mathrm{OH})\right]$ (3), containing interstitial $\mathrm{Mn}(॥), \mathrm{Fe}(॥)$ and $\mathrm{Ga}(॥ 1)$ dopant ions, shows that transition metal doping alone does not lower the band gaps below that of $\mathrm{TiO}_{2}$ or the corresponding metal-doped $\mathrm{TiO}_{2}$. Instead, the band gaps of these cages are within the range of values found previously for transition metal-doped $\mathrm{TiO}_{2}$ nanoparticles. The low band gaps previously reported for 1 and for a recently reported related $\mathrm{Mn}$-doped POT cage appear to be the result of low band gap impurities (most likely amorphous $\mathrm{Mn}$-doped $\mathrm{TiO}_{2}$ ).
\end{abstract}

\section{Introduction}

Titania, $\mathrm{TiO}_{2}$, is a technologically important, environmentally benign semiconductor which has drawn much attention over the past decades due to its long-term chemical stability and numerous applications in photocatalytic, photovoltaic and sensing devices. ${ }^{1}$ However, owing to its high band gap (ca. 3.20 $\mathrm{eV})$ only the ultraviolet region of the solar light $(<5 \%$ of solar

\footnotetext{
${ }^{a}$ Chemistry Department, Cambridge University, Lensfield Road, Cambridge CB2 1EW, UK. E-mail: dsw1000@cam.ac.uk; Fax:+44 (0)1223 336362;

Tel: +44 (0)1223 763122 (or 336333)

${ }^{b}$ Department of Chemistry, Tongjii University, 1239 Siping Road, Shanghai, 20092,

P. R. China. E-mail: ganlh@tongii.edu.cn

${ }^{c}$ The School of Natural and Computing Sciences, Weston Building, Weston Walk, Aberdeen CB24 3UE, UK

${ }^{d}$ Instituto de Ciencia de Materiales de Sevilla CSIC-Universidad Sevilla, Av. Américo Vespucio 49, 41092 Sevilla, Spain

${ }^{e}$ Chemistry Department, University of Liverpool, Liverpool L69 7ZD, UK

${ }^{f}$ Institut für Anorganische Chemie, University of Karlsruhe, Engesserstr. 15,

76131 Karlsruhe, Germany

$\dagger$ Electronic supplementary information (ESI) available: SEM and EDS of 2 and $\mathbf{3}$, solid-state ${ }^{71} \mathrm{Ga}$ NMR for 3, BVS analysis of $\mathbf{1}, \mathbf{2}$ and 3, band gap determination for 1, 2, 3 and 5 using a direct band gap semiconductor model, powder XRD of crystalline 5 and the impurity phase, XPS of 1, 2 and 5. CCDC 984451, 984452, 984453 and 984454 . For ESI and crystallographic data in CIF or other electronic format see DOI: 10.1039/c4dt00555d
}

flux on Earth) can be harnessed in photoexcitation processes. Doping of foreign non-metals ${ }^{2}$ or metals ${ }^{3}$ into $\mathrm{TiO}_{2}$ has been shown to have a dramatic effect on extending the absorption into the visible region. ${ }^{4}$ Previous studies have shown that the properties of metal-doped titania depend substantially on both the metal ion incorporated, its concentration and the structure and binding mode of the dopant metal ions within the host lattice.

Numerous density function theory (DFT) calculations have investigated the structural and electronic consequences of inclusion of dopants into $\mathrm{TiO}_{2}{ }^{5}$ These confirm that the presence of metal or non-metal atoms within the bulk lattice of $\mathrm{TiO}_{2}$ is responsible for the modification of the band gap and optical properties, by creating hole or electron states. However, there are major problems with such calculations, particularly the underestimation of band gaps and the inability to describe properly localised defect states in metal oxides. ${ }^{6}$

Structurally well-defined heterometallic polyoxotitanate (POT) cages of the type $\left[\mathrm{Ti}_{x} \mathrm{O}_{y}(\mathrm{~L})_{z} \mathrm{M}_{n} \mathrm{X}_{m}\right]$ [where $\mathrm{M}$ is a dopant ion, $\mathrm{L}=$ an organic anion (e.g., $\mathrm{OR}$ ), and $\mathrm{X}$ is an inorganic anion (such as a halide)], can be regarded as ligand-stabilised fragments of the metal-doped $\mathrm{TiO}_{2}$ and their study by singlecrystal X-ray diffraction provides another approach to understanding host-guest behaviour in this area. ${ }^{7,8}$ These welldefined, organically-soluble species can be employed as singlesources precursors for the hydrolytic deposition of metal- 
doped titania $^{7 f-h}$ and have potential applications as photocatalytic redox systems in chemical reactions. In relation to this last potential application, recently it was reported that the $\mathrm{Mn}^{\mathrm{II}}$ cage $\left[\mathrm{Ti}_{14} \mathrm{O}_{14}(\mathrm{OH})_{2}(\mathrm{OEt})_{28} \mathrm{Mn}\right](\mathbf{1})$, containing an interstitial $\mathrm{Mn}^{\mathrm{II}}$ ion, has an exceptionally low band gap of $2.65 \mathrm{eV}^{8 a}$ Further reports by the same authors have also suggested that band gaps of $c a$. 2.57-2.74 eV are normal for $\mathrm{Mn}^{\mathrm{II}}$-doped POT cages. $^{8 b, c}$ Remarkably, these band gaps are ca. $0.6 \mathrm{eV}$ lower than that of $\mathrm{TiO}_{2}$ itself and similar to the lowest band gap
$\mathrm{FeSO}_{4} \cdot \mathrm{H}_{2} \mathrm{O}$ gives a mixture of the crystalline compounds $\left[\mathrm{GaTi}_{14}(\mathrm{OEt})_{28} \mathrm{O}_{15}(\mathrm{OH})\right]$ (3) (major), $\left[(\mathrm{GaCl})_{2} \mathrm{Ti}_{14}(\mathrm{OEt})_{20} \mathrm{O}_{20}\right]$ (4) (minor) and $\left[\mathrm{Ti}_{16} \mathrm{O}_{16}(\mathrm{OEt})_{32}\right]$ (minor) (eqn (2)) (see Experimental section). In this case it was found that the product ratio of cages 3 to 4 depended on the dryness of the EtOH solvent. If $95 \%$ $\mathrm{EtOH}$ is used as the solvent then more of $\mathbf{4}$ is generated. This is presumably a consequence of the greater water content of the solvent which results in a higher condensation ratio of 4 $\left(\mathrm{Ti}: \mathrm{O}_{\text {oxo }}=1.43\right)$ compared to $3\left(\mathrm{Ti}: \mathrm{O}_{\text {oxo }}=1\right)$.

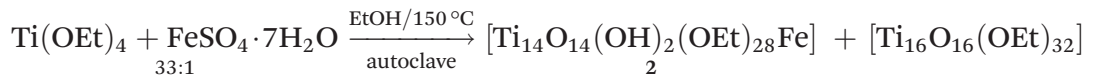

$$
\begin{aligned}
& \mathrm{Ti}(\mathrm{OEt})_{33: 1}+\mathrm{GaCl}_{3} \underset{\text { atoclave }}{\stackrel{\mathrm{EtOH} / 150^{\circ} \mathrm{C}}{\longrightarrow}}\left[\mathrm{GaTi}_{14}(\underset{3}{\mathrm{OEt}})_{28} \mathrm{O}_{15}(\mathrm{OH})\right]+\left[(\mathrm{GaCl})_{2} \mathrm{Ti}_{\mathbf{4}}(\mathrm{OEt})_{20} \mathrm{O}_{20}\right]+\left[\mathrm{Ti}_{16} \mathrm{O}_{16}(\mathrm{OEt})_{32}\right]
\end{aligned}
$$

found for $\mathrm{Mn}^{\mathrm{II}}$-doped $\mathrm{TiO}_{2}\left(2.73 \mathrm{eV}\right.$, with $0.06 \mathrm{wt} \%$ doping). ${ }^{9}$ If correct, such low band gap cages might well be functional photocatalytic redox systems in their own right.

Coincidently, in on-going studies in this area we had structurally characterised other cages closely related to 1 containing $\mathrm{Fe}^{\mathrm{II}}$ and $\mathrm{Ga}^{\mathrm{III}}$ ions within the same cage arrangement, which provide a unique opportunity to explore the electronic influence of metal ions alone with the same cage architecture. Here we explore the band gap behaviour of the series of cages $\mathbf{1}$, $\left[\mathrm{Ti}_{14} \mathrm{O}_{14}(\mathrm{OH})_{2}(\mathrm{OEt})_{28} \mathrm{Fe}\right](2)$ and $\left[\mathrm{Ti}_{14} \mathrm{O}_{14}(\mathrm{OH})(\mathrm{OEt})_{28} \mathrm{Ga}\right](3)$ and the origin of the reported low band gap of 1 and related $\mathrm{Mn}^{\mathrm{II}}$ doped POT cages. Our conclusion is that the previously reported band gap of $\mathbf{1}$ is in error and that the true value of the band gap is $3.36 \mathrm{eV}$ (i.e., $0.7 \mathrm{eV}$ higher than reported). The results suggest that sample contamination, most likely by amorphous $\mathrm{Mn}$-doped $\mathrm{TiO}_{2}$, is the origin of the unusually low reported band gaps in this and related studies of $\mathrm{Mn}^{\mathrm{II}}$ POT cages. Importantly, our results place the magnitude of the band gaps of solid transition metal-doped POT cages above those of the corresponding metal-doped $\mathrm{TiO}_{2}$ solid-state materials but within the range of metal-doped nanoparticles.

\section{Results and discussion}

\subsection{Synthesis and characterisation of new metal-doped cages}

The solvothermal reaction of $\mathrm{Ti}(\mathrm{OEt})_{4}$ with $\mathrm{FeSO}_{4} \cdot 7 \mathrm{H}_{2} \mathrm{O}$ (33:1 molar equivalents) in $\mathrm{Mg}$-dried, distilled ethanol at $150{ }^{\circ} \mathrm{C}$ in a teflon-line autoclave followed by slow cooling to room temperature gives a crop of colourless crystals, consisting of the yellow-brown crystals of the $\mathrm{Fe}^{\mathrm{II}}$ POT $\left[\mathrm{Ti}_{14} \mathrm{O}_{14}(\mathrm{O}-\right.$ $\left.\mathrm{H})_{2}(\mathrm{OEt})_{28} \mathrm{Fe}\right](2)$ contaminated with the previously reported $\mathrm{Ti}_{16}$ cage $\left[\mathrm{Ti}_{16} \mathrm{O}_{16}(\mathrm{OEt})_{32}\right]$ (white crystals) ${ }^{10}$ (eqn (1)) (see Experimental section). The same reaction involving $\mathrm{GaCl}_{3}$ in place of
The new cages 2, 3 and 4 can be separated manually under a microscope. Although they were isolated in air from the autoclaves, the compounds were stored under nitrogen in a glove box to prevent hydrolysis of the potentially reactive Ti-OEt bonds. Compounds 2 and 3 were fully characterised using a combination of elemental $(\mathrm{C}, \mathrm{H})$ analysis, IR spectroscopy, solution-state ${ }^{1} \mathrm{H}$ and solid-state ${ }^{71} \mathrm{Ga}$ NMR spectroscopy (ESI, section ESI- $3 \dagger$ ), Energy Dispersive X-ray Spectroscopy (EDS) (ESI, section ESI-section $1 \dagger$ ) and X-ray Photoelectron Spectroscopy (XPS) (ESI, section ESI-9†). Single-crystal X-ray diffraction (XRD) studies of $\mathbf{2}$ and $\mathbf{3}$ were undertaken. Since $\mathbf{4}$ is only obtained as a minor component in the synthesis of $\mathbf{3}$, it was characterised by a single-crystal X-ray study alone.

During the course of comparative studies of the band gaps of 1,2 and 3, cage 1 was synthesised using the literature procedure from the autoclave reaction of $\mathrm{Mn}(\mathrm{AcO})_{3} \cdot 2 \mathrm{H}_{2} \mathrm{O}$ (Aldrich 97\%) with $\mathrm{Ti}(\mathrm{OEt})_{4}$ in EtOH at $150{ }^{\circ} \mathrm{C}$ (eqn (3)). ${ }^{8}$ Powder XRD studies of samples of $\mathbf{1}$ prepared in this way always showed the presence of $\left[\mathrm{Ti}_{16} \mathrm{O}_{16}(\mathrm{OEt})_{32}\right]$ as well as another impurity, whose amount varied significantly from batch to batch (see Fig. 4a). The single-crystal XRD study of this species shows it to be the $\mathrm{K} / \mathrm{Mn}$ cage $\left[\mathrm{Ti}_{27} \mathrm{MnKO}_{35}(\mathrm{OH})_{2}(\mathrm{OEt})_{39}\right]_{0.33}\left[\mathrm{Ti}_{28} \mathrm{MnKO}_{37}(\mathrm{OH})-\right.$ $\left.(\mathrm{OEt})_{40}\right]_{0.67}$ (5) (see Fig. 3). The unexpected presence of a potassium ion in the structure of $\mathbf{5}$ is explained by the way in which commercially-supplied $\mathrm{Mn}(\mathrm{AcO})_{3} \cdot 2 \mathrm{H}_{2} \mathrm{O}$ is prepared, by the oxidation reaction of $\mathrm{Mn}(\mathrm{AcO})_{2}$ with $\mathrm{KMnO}_{4}$ in AcOH. ${ }^{11}$ XPS indicates that the oxidation state of the manganese in $\mathbf{5}$ is $\mathrm{Mn}$ (II), although the complexity of the spectrum does not allow exclusion of a small contribution from Mn(III) (ESI, section ESI-8 $\dagger$ ). The presence of potassium and $\mathrm{Mn}$ ions in $\mathbf{5}$ was confirmed by a TEM-EDS study (ESI, section ESI-2†). Cage 5 was also synthesised separately (free from 1) by the reaction of $\mathrm{Mn}$ $(\mathrm{AcO})_{3} \cdot 2 \mathrm{H}_{2} \mathrm{O}$ with $\mathrm{KAcO}$ and $\mathrm{Ti}(\mathrm{OEt})_{4}$ in $\mathrm{EtOH}$ in an autoclave at $150{ }^{\circ} \mathrm{C}$ (eqn (4)) and its bulk purity confirmed by a powder XRD study and elemental (C, H) analysis (see Experimental section).

$$
\begin{aligned}
\mathrm{Ti}(\mathrm{OEt})_{4} & +\underset{15: 1}{\mathrm{Mn}(\mathrm{AcO})_{3} \cdot 2 \mathrm{H}_{2} \mathrm{O}} \underset{\text { autoclave }}{\stackrel{\mathrm{EtOH} / 150^{\circ} \mathrm{C}}{\longrightarrow}}\left[\mathrm{Ti}_{14} \mathrm{O}_{14}(\mathrm{OH})_{2}(\mathrm{OEt})_{28} \mathrm{Mn}\right]+\left[\mathrm{Ti}_{27} \mathrm{MnKO}_{35}(\mathrm{OH})_{2}(\mathrm{OEt})_{39}\right]_{0.33}\left[\mathrm{Ti}_{28} \mathrm{MnKO}_{37}(\mathrm{OH})(\mathrm{OEt})_{40}\right]_{0.67} \\
& +\left[\mathrm{Ti}_{16} \mathrm{O}_{16}(\mathrm{OEt})_{32}\right]
\end{aligned}
$$




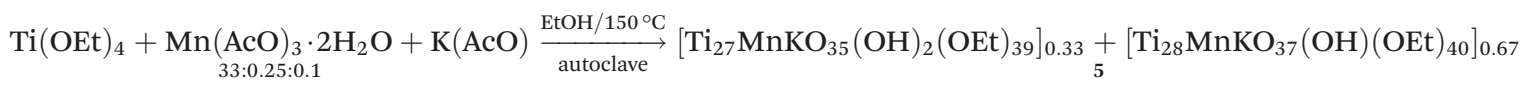

The single-crystal X-ray diffraction (XRD) studies of 2 and 3 reveal the same roughly spherical arrangement for both (Fig. 1a) (see Experimental section for crystallographic details). The structural arrangements are identical to that found for the previously reported cage 1 , the only crystallographic difference being that 2 and 3 readily refine in the more symmetric $I \overline{4} 2 \mathrm{~m}$ space group rather than as a merohedral twin in $I \overline{4}$ reported for $1,{ }^{8}$ which lead to no improvement in the refinements of 2 and 3. A phase change between the temperatures of the data collections of 2 and 3 (180(2) and 150(2) K, respectively) and that for $\mathbf{1}(90(2) \mathrm{K})^{8}$ would account for this difference but was not investigated further in our study.

The structures of 2 and 3 can be viewed as comprising of $\left[\mathrm{Ti}_{14}(\mathrm{OEt})_{28} \mathrm{O}_{14}(\mathrm{OH})_{2}\right]^{2-}$ or $\left[\mathrm{Ti}_{14}(\mathrm{OEt})_{28} \mathrm{O}_{15}(\mathrm{OH})\right]^{3-}$ anion 'hosts' which encapsulate $\mathrm{Fe}^{2+}$ or $\mathrm{Ga}^{3+}$ cations at the centres of the

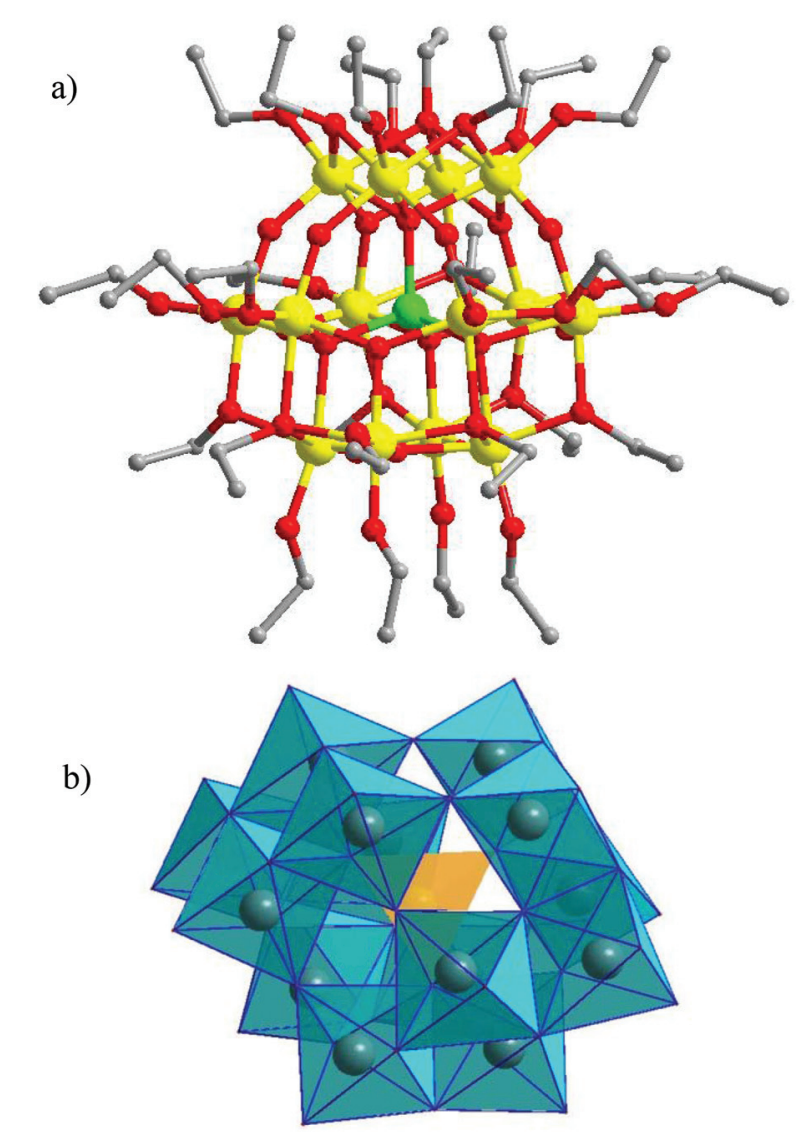

Fig. 1 (a) Solid-state structures of the cages 2 and 3. $\mathrm{H}$-atoms and the disorder of some of the Et-groups are omitted for clarity. Selected bond lengths $(\AA \AA)$ and angles $\left({ }^{\circ}\right) ; 2, \mathrm{Fe}-\mathrm{O}$ 1.906(6), Ti-O $\mathrm{O}_{\text {oxo }}$ range 1.768(5)2.291(5), $\mathrm{Ti}-\mathrm{O}(\mathrm{Et})$ range $1.787(7)-2.063(6), \mathrm{O}-\mathrm{Fe}-\mathrm{O}$ range 107.2(2)114.1(3). 3, Ga-O 1.877(5), Ti-O oxo range 1.764(4)-2.294(5), $\mathrm{Ti}-\mathrm{O}(\mathrm{Et})$ range 1.788(6)-2.064(6), O-Ga-O range 107.4(2)-113.7(3) (approximate diameter of the cores of 2 and 3, $6.8 \AA$ ) (red $=0$, yellow $=\mathrm{Ti}$, green $=\mathrm{Fe}$ or $\mathrm{Ga}$ ). (b) The polyhedral representation of the core structures, showing the fourteen edge and corner-sharing $\mathrm{TiO}_{6}$ octahedra forming the 'host'. cages. The POT units are constructed from fourteen interlocked edge and corner-sharing octahedral $\mathrm{TiO}_{6}$ units (Fig. 1b) and differ only in the extent of protonation of the O-atoms of the cores (with two $\mathrm{OH}$ groups in 2 and one in 3 ). The presence of exclusively six-coordinate $\mathrm{Ti}$ in $\mathbf{2}$ and $\mathbf{3}$ is in common with the main polymorphs of $\mathrm{TiO}_{2} \cdot{ }^{12}$ As a result of the symmetry of the cages, the $\mathrm{OH}$ groups present in both of the cages could not be identified from the X-ray structures, however, the solidstate IR spectra of both cages contain weak $\mathrm{O}-\mathrm{H}$ stretching bands. The Fe/Ga : Ti ratio of $1: 14$ found in both cages is confirmed by Energy Dispersive X-ray Spectroscopy (EDS) which shows typical ratios of $\mathrm{Ga}$ and $\mathrm{Fe}: \mathrm{Ti}$ of $1: 13.2$ for 2 and $1: 14.3$ for 3 (ESI, section ESI- $1 \dagger$ ).

The formal oxidation states of the central $\mathrm{Fe}$ and $\mathrm{Ga}$ atoms in 2 and 3 were initially investigated using bond-valence sum (BVS) calculations (ESI, section ESI- $4 \dagger$ ). ${ }^{13}$ These show that the Fe in 2 has a valence of 1.87-2.05 whereas the valence of the $\mathrm{Ga}$ in 3 is 2.63 (ESI $\dagger$ ). The lower than expected value for 3 may be a result of the tetrahedral hole at the centre of the cage being slightly larger than ideal for the smaller $\mathrm{Ga}^{3+}$ ion (i.e., ionic radii of $\mathrm{Fe}^{2+} 0.78 \AA$ vs. $\mathrm{Ga}^{3+} 0.62 \AA$ and $\left.\mathrm{Mn}^{2+} 0.83 \AA\right) .{ }^{14}$ The presence of $\mathrm{Fe}(\mathrm{II})$ in cage 2 was also indicated experimentally by a detailed peak-fitting analysis of the XPS spectrum (ESI, section ESI-8†), while the observation of a single resonance in the solid-state ${ }^{71} \mathrm{Ga}$ MAS-NMR of 3 at ca. $\delta 50 \mathrm{ppm}$ is consistent with tetrahedral $\mathrm{Ga}^{3+}$ (ESI, section ESI- $3 \dagger) .{ }^{15}$ The Fe-O [1.906(6) $\left.\AA\right]$ and Ga-O [1.877(5) $\left.\AA\right]$ bond lengths found in the structures of 2 and 3 are also within the range observed in other structurally-characterised compounds containing $\mathrm{Fe}^{2+}$ and $\mathrm{Ga}^{3+}$ coordinated by four tetrahedral O-ligands. ${ }^{16}$ For completeness a BVS calculation on the Mn cage 1 was also undertaken, giving a valence of 1.94 for the Mn centre (ESI, section ESI- $4 \dagger$ ) and adding further support to the previous assignment of the oxidation state made on the basis of bond length analysis and X-ray Absorption Near-Edge Structure (XANES) spectroscopy. ${ }^{8}$ A peak-fitting analysis of the XPS spectrum of $\mathbf{1}$ as part of the current study also indicates the presence of $\mathrm{Mn}^{\mathrm{II}}$ (ESI, section ESI- $8 \dagger$ ).

The other species isolated from the reaction of $\mathrm{GaCl}_{3}$ with $\mathrm{Ti}(\mathrm{OEt})_{4}$, the cage $\left[\mathrm{Ti}_{14} \mathrm{O}_{20}(\mathrm{OEt})_{20}(\mathrm{GaCl})_{2}\right](4)$, has a centrosymmetric arrangement containing a $\mathrm{Ti}_{14} \mathrm{Ga}_{2}$ metal stoichiometry, in which the two $\mathrm{GaCl}$ units lie on either side of the core at the periphery of the cage structure (Fig. 2a) (see Experimental section for crystallographic details). As in the cases of 2 and 3 , the POT anion unit $\left[\mathrm{Ti}_{14} \mathrm{O}_{20}(\mathrm{OEt})_{20}\right]^{2-}$ is constructed from fourteen interlocked $\mathrm{TiO}_{6}$ units, now with a roughly cylindrical arrangement (Fig. 2b). The inner cavity of the $\left[\mathrm{Ti}_{14} \mathrm{O}_{20}(\mathrm{OEt})_{20}\right]^{2-}$ unit in $\mathbf{4}$ does not appear to have the appropriate geometry or dimensions to allow the coordination of $\mathrm{Ga}^{3+}$ cations, with $\mathrm{O}$... O distances of $c a$. 3.6-5.4 $\AA$ between four misaligned $\mu_{5}-\mathrm{O}$ potential coordination sites. As expected, the BVS analysis of $\mathbf{4}$ gives a value of 2.89 for valence of the Ga atoms (ESI, section ESI- $4 \dagger$ ). 


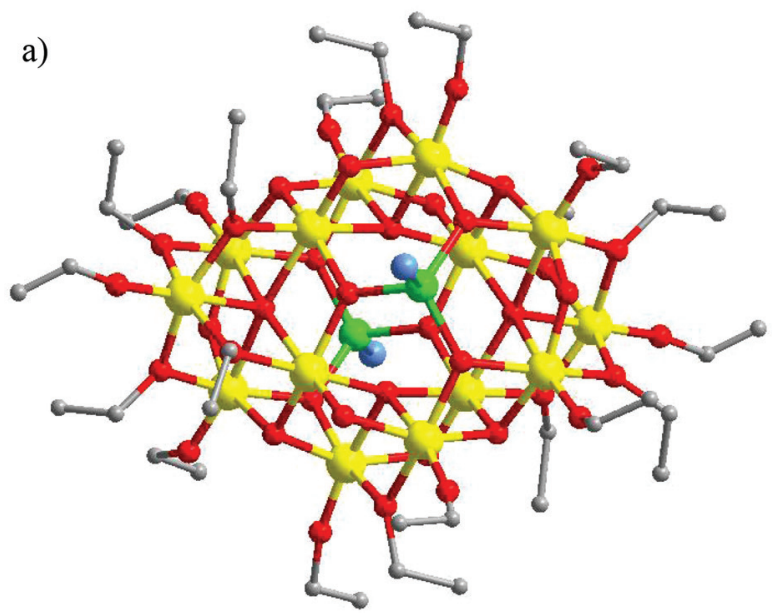

b)

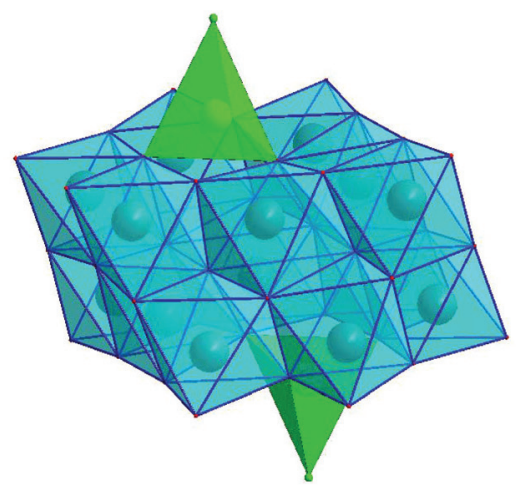

Fig. 2 (a) Solid state structure of the cage 4 . $\mathrm{H}$-atoms and the disorder of some of the Et-groups are omitted for clarity. Selected bond lengths (Å) and angles ( ${ }^{\circ}$; $\mathrm{Ga}-\mathrm{O}$ range $1.850(5)-1.859(5), \mathrm{Ga}-\mathrm{Cl} 2.172(2), \mathrm{Ti}-\mathrm{O}_{\text {oxo }}$ range 1.789(4)-2.318(4), $\mathrm{Ti}-\mathrm{O}(\mathrm{Et})$ range 1.739(5)-2.042(5) (approximate dimensions of the core, $9 \times 5 \AA)($ red $=0$, yellow $=\mathrm{Ti}$, green $=\mathrm{Ga}$, blue $=$ $\mathrm{Cl}$ ). (b) The polyhedral representation of the core structure, showing the fourteen edge and corner-sharing $\mathrm{TiO}_{6}$ octahedra with the tetrahedral Ga-environments located on the top and bottom of the cage.

The single-crystal X-ray analysis of $\left[\mathrm{Ti}_{27} \mathrm{MnKO}_{35^{-}}\right.$ $\left.(\mathrm{OH})_{2}(\mathrm{OEt})_{39}\right]_{0.33}\left[\mathrm{Ti}_{28} \mathrm{MnKO}_{37}(\mathrm{OH})(\mathrm{OEt})_{40}\right]_{0.67}$ (5) shows it to be a $\mathrm{K}^{+} / \mathrm{Mn}^{\text {II }}$ POT cage (Fig. 3), which consists of two separate cage structures in a ratio of $2: 1$. These cages have the same overall arrangement but differ in the presence or absence of a Ti$(\mathrm{OEt})_{2}$ fragment and in the number of $\mathrm{OH}$ groups (required for each cage to attain neutrality). The overall structural arrangement of the cage units and the type of site disorder found in $\mathbf{5}$ is similar to that observed in related lanthanide $(\mathrm{La}, \mathrm{Ce})^{7 e}$ and alkali metal $(\mathrm{Na}, \mathrm{Li})^{17}$ doped POT cages. ${ }^{17}$ Like these previously reported cages, the $\mathrm{K}^{+}$cation in $\mathbf{5}$ is coordinated at the bottom of the cage by six O-atoms in a crown-like arrangement. The structure is also very similar to that of $\left[\mathrm{Ti}_{28} \mathrm{MnO}_{36}(\mathrm{OH})(\mathrm{OEt})_{40}\right]$ published recently, also using $\mathrm{Mn}(\mathrm{AcO})_{3} \cdot 2 \mathrm{H}_{2} \mathrm{O}$ as the source of $\mathrm{Mn}^{\mathrm{II}} .^{8 c}$ In this case, however, only a single $\mathrm{Ti}_{28}$ component is found in the structure and the $\mathrm{K}^{+}$cation is replaced by an $\mathrm{H}$-bonded water molecule.

\subsection{Band gap determination}

We first assessed the bulk purity of 1, 2 and $\mathbf{3}$ and their stability to atmospheric hydrolysis by obtaining the powder XRD

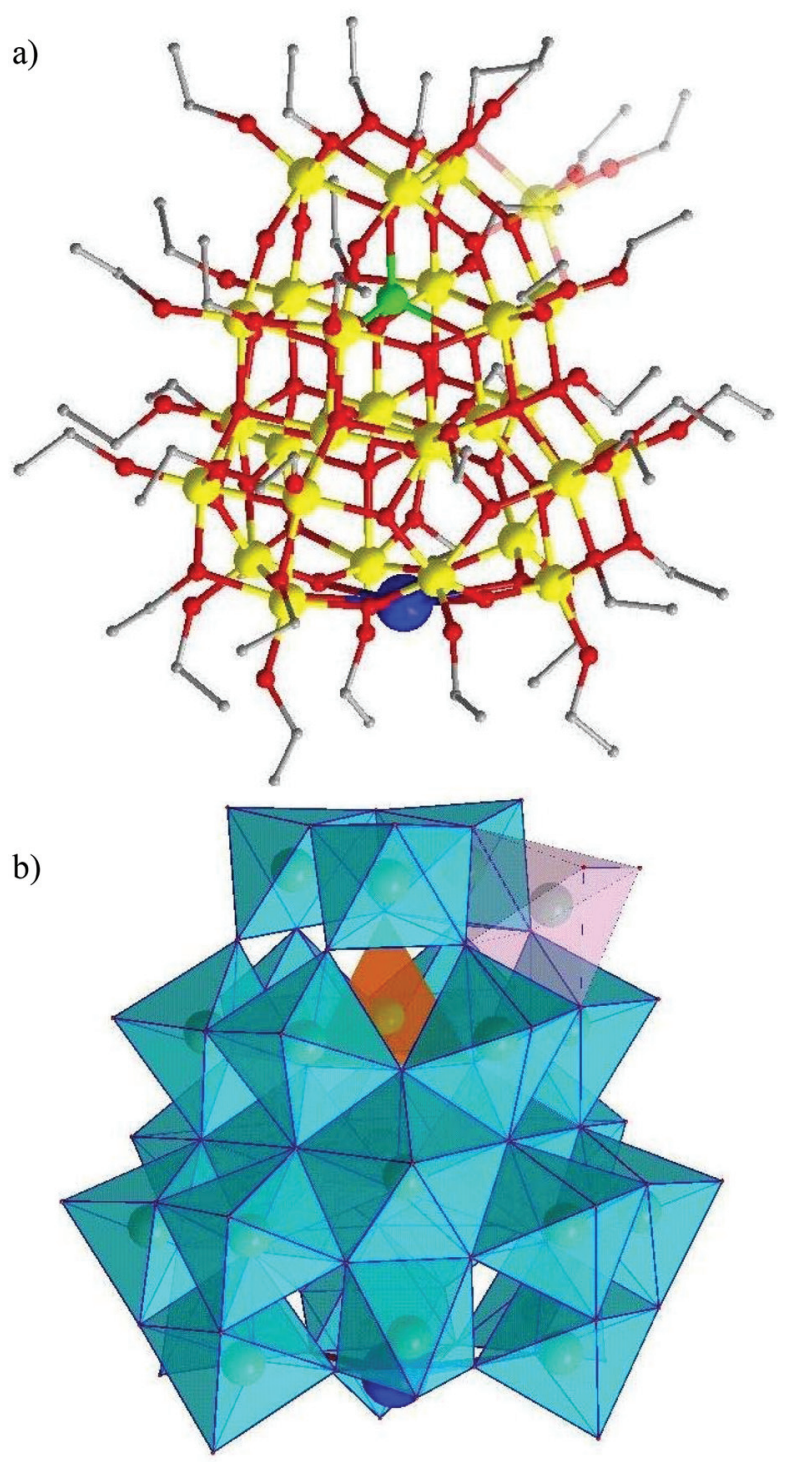

Fig. 3 (a) Solid state structure of the cage $\mathbf{5}$. $\mathrm{H}$-atoms are omitted for clarity. The $\mathrm{Ti}(\mathrm{OEt})_{2}$ fragment present in the major component is transparent. Selected bond lengths ( $\AA$ ); $\mathrm{Mn}-\mathrm{O}$ range 1.989(6)-2.040(6), K-O range 2.684(7) $-2.762(7)$, (red $=\mathrm{O}$, yellow $=\mathrm{Ti}$, green $=\mathrm{Mn}$, blue $=\mathrm{K})$. $(\mathrm{b})$ The polyhedral representation of the core structure of 5 .

data on freshly prepared, purified samples and comparing these to samples that had been exposed to air for prolonged periods. Our previous experience of metal-doped POT cages is that they can vary greatly in their stability to hydrolysis and, indeed, they decompose hydrolytically to give metal-doped $\mathrm{TiO}_{2}$, often with retention of the stoichiometry present in the original POT cages. ${ }^{7}$ The presence of metal-doped $\mathrm{TiO}_{2}$ contamination would seriously affect the reliability of band gap determination derived from UV-visible optical reflectance spectra, potentially leading to underestimation of the band gaps.

Representative powder XRD data for $\mathbf{1}$ (as prepared using the literature procedure), ${ }^{8 a} 2$ and 3 are shown in Fig. 4. All powder XRD spectra were obtained in air with no special hand- 
a)

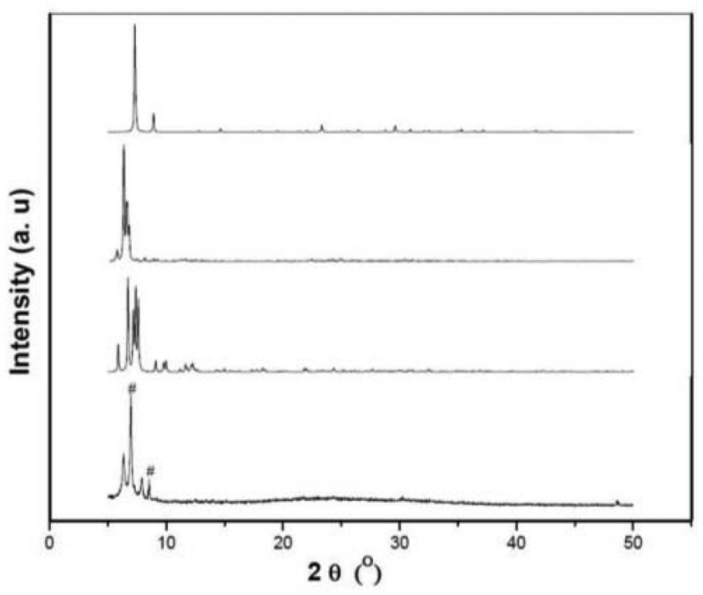

b)
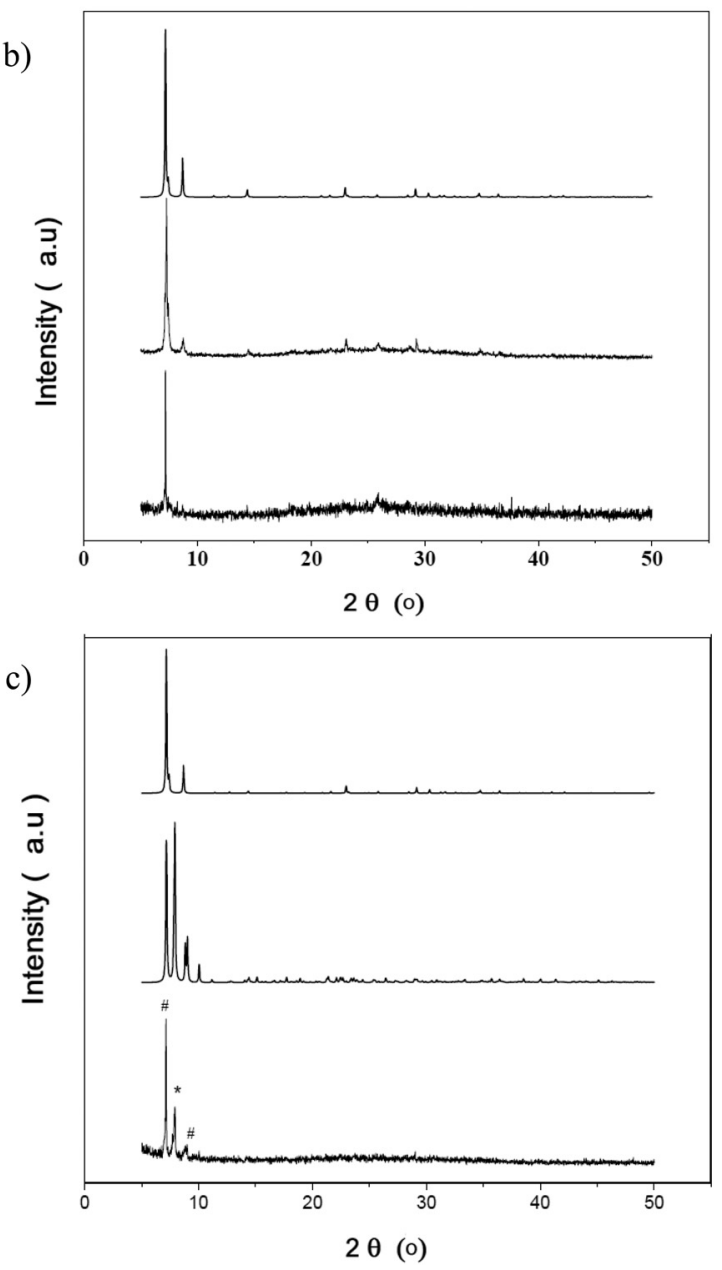

Fig. 4 (a) The calculated powder XRD spectrum of 1 (top), the calculated powder XRD spectrum of 5 (second from top), the calculated powder XRD of $\left[\mathrm{Ti}_{16} \mathrm{O}_{16}(\mathrm{OEt})_{32}\right]$ (second from bottom) and the experimental powder XRD data for a fresh, manually-purified sample of 1 (bottom) (the peaks marked \# are those for 1), (b) the calculated powder XRD spectrum of 2 (top), the experimental powder XRD data for a fresh, manually-purified sample of $\mathbf{2}$ (middle) and after prolonged air exposure (24 h) (bottom), (c) The calculated powder XRD spectrum of 3 (top), the calculated powder XRD spectrum of 4 (middle) and the experimental powder XRD data for a fresh sample of 3 (bottom) (the peaks marked \# are those for 3 ).

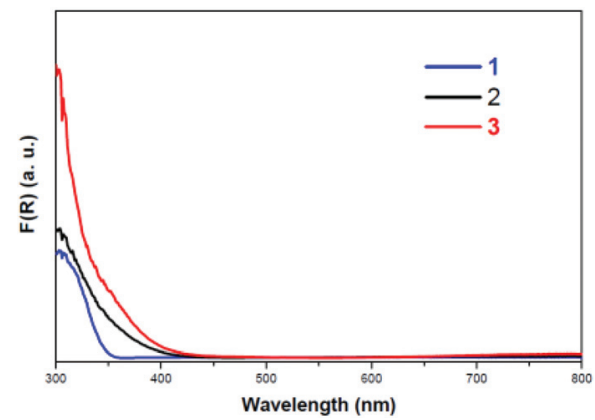

Fig. 5 Diffuse reflectance spectra of solid 1, 2 and 3 at the absorption edges. $F(R)$ is the Kubelka-Munk function.

ling procedures being employed. While samples of the Fe cage 2 can be obtained in high purity (Fig. $4 \mathrm{~b}$ ), it proved impossible to eliminate completely the impurities from $\mathbf{1}$ (i.e., $\left[\mathrm{Ti}_{16} \mathrm{O}_{16}(\mathrm{OEt})_{32}\right]$ and 5, Fig. 4a) and $\mathbf{3}$ (i.e., $\left[\mathrm{Ti}_{16} \mathrm{O}_{16}(\mathrm{OEt})_{32}\right]$ and 4, Fig. 4c) by manual separation under a microscope. This is because $\mathbf{1}$ and $\mathbf{3}$ form colourless crystals and the contaminants are also present as colourless crystals. This is unlike the situation with the Fe cage $\mathbf{2}$ which is yellow-brown in colour and can be easily separated from the colourless crystals of $\left[\mathrm{Ti}_{16} \mathrm{O}_{16}(\mathrm{OEt})_{32}\right]$ by eye. It is clear from the powder XRD data that all of the compounds are air stable, at least for the $c a .1 \mathrm{~h}$ period involved in grinding crystalline samples and collecting XRD data. In fact, powdered samples of 2 only begin to degrade after about $24 \mathrm{~h}$, with a noticeable loss of crystallinity (as shown in the bottom panel in Fig. 4b).

The UV-visible diffuse reflectance spectra of freshly prepared samples of solid 1, 2 and 3 are shown in Fig. 5 at their absorption edges. This is associated with the $\mathrm{O} \rightarrow \mathrm{Ti}$ charge transfer transition in their $\mathrm{Ti}_{x} \mathrm{O}_{y}$ cores, from which the band gap of the POT cages can be determined. In order to allow direct comparison of the calculated band gaps with that previously reported for $\mathbf{1},{ }^{8 a}$ the same method of analysis was employed in which the band gap is estimated directly by extrapolation of the absorption edge data to the energy axis. ${ }^{8}$ This is shown for 1, 2 and 3 in Fig. 6, from which we estimate the band gap of 1 to be $3.36 \mathrm{eV}$, for $23.22 \mathrm{eV}$ and for $33.57 \mathrm{eV}$. The band gap we obtain for $\mathbf{1}$ is therefore around $0.7 \mathrm{eV}$ higher than reported previously. ${ }^{8 a}$ In order to provide a comparison of these band gaps with a similarly-sized undoped POT cage and to give an estimate of the errors involved, we also determined the band gaps of $\left[\mathrm{Ti}_{16} \mathrm{O}_{16}(\mathrm{OEt})_{32}\right]$ and $\mathrm{P} 25 \mathrm{TiO}_{2}$ using the same method, values of $3.63 \mathrm{eV}$ and $2.98 \mathrm{eV}$ (lit. $3.20 \mathrm{eV}$ ) were obtained (see ESI, section ESI-5†).

For further comparison with the above band gap determinations, we also analysed the UV-visible data using a direct band gap semiconductor model (ESI, section ESI- $5 \dagger$ ). ${ }^{18}$ This analysis gave values of $3.58 \mathrm{eV}$ for $\mathbf{1}, 3.56 \mathrm{eV}$ for 2 and $3.69 \mathrm{eV}$ for 3. The band gaps for $\left[\mathrm{Ti}_{16} \mathrm{O}_{16}(\mathrm{OEt})_{32}\right]$ and $\mathrm{P} 25 \mathrm{TiO}_{2}$ were found to be $3.73 \mathrm{eV}$ and $3.19 \mathrm{eV}$, respectively. These results are not dissimilar to the band gaps obtained by direct analysis of the absorption edge, which are consistently $c a .0 .2 \mathrm{eV}$ lower than those obtained using the direct band gap semiconductor 

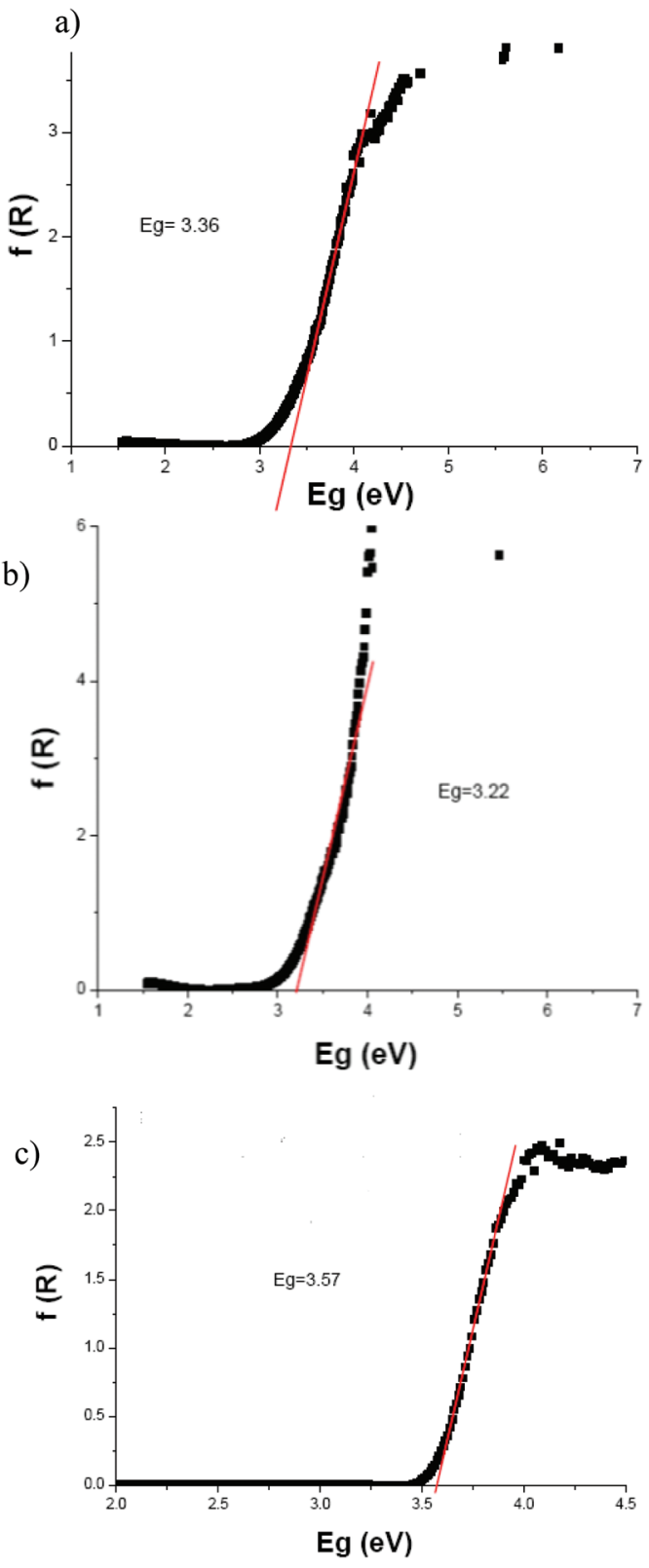

Fig. 6 Determination of the band gaps in 1, 2 and 3 using direct analysis of the absorption edges, by extrapolation to the energy, (a) 1, (b) 2 and (c) 3 .

model but show the same overall trend that the band gap of $\mathbf{1} \approx \mathbf{2}<3$. From these data it can also be concluded that whereas $\mathrm{Mn}^{\mathrm{II}}$ or $\mathrm{Fe}^{\mathrm{II}}$ doping reduces the band gap compared to the similarly-sized undoped $\left[\mathrm{Ti}_{16} \mathrm{O}_{16}(\mathrm{OEt})_{32}\right]$ POT cage, $\mathrm{Ga}^{\mathrm{III}}$ doping has little or no effect. It is also clear that the band gaps of 1, 2 and 3 are all higher than that of $\mathrm{TiO}_{2}$ by $c a .0 .2-0.6 \mathrm{eV}$ and significantly higher than the band gaps of $\mathrm{Mn}$ - and Fedoped $\mathrm{TiO}_{2}$ (with lowest values reported of $2.73^{9}$ and $2.67 \mathrm{eV},{ }^{19}$ respectively). ${ }^{20}$

The optical behaviour of the $\mathrm{Mn}^{\mathrm{II}}$ cages 5 (see Fig. 7, red trace) is unusual compared to the other cages in that its UVvisible spectrum contains an additional minor absorption

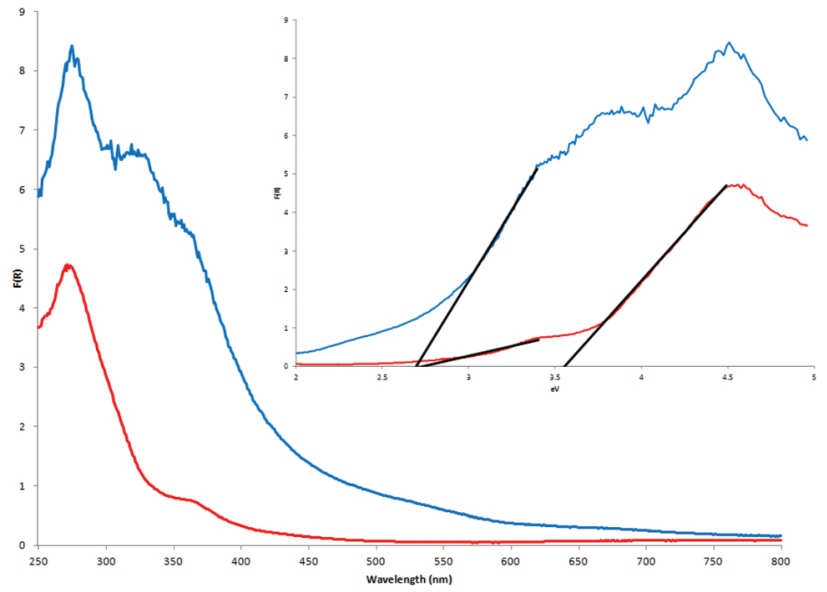

Fig. 7 The UV-visible spectrum of a freshly prepared crystalline sample of 5 (red) and of the finely-divided powder impurity present in the synthesis of 5 (blue). The insert shows the band gap determination of both components in 'as prepared' 5 (red trace) and in the impurity phase (blue trace) using the direct analysis of the absorption edge. The black lines are the statistical best-fit lines over the data range indicated. Note that the band gap of the shoulder in $\mathbf{5}$ is almost identical to that in the impurity.

band at $c a .375 \mathrm{~nm}$, which is responsible for the absorption edge reaching well beyond that of 1,2 and 3 and into the visible region (up to $c a .500 \mathrm{~nm}$ ). One possible explanation for the minor absorption band in $\mathbf{5}$ is revealed by Density of States (DOS) calculations in which the $\mathrm{Mn}^{\mathrm{II}}$ ion of the $\mathrm{Ti}_{28}$ cage component is substituted by a $\mathrm{Mn}^{\mathrm{III}}$ ion (see ESI, section ESI-9†). The resulting neutral cage, $\left[\mathrm{Ti}_{28} \mathrm{MnKO}_{38}(\mathrm{OEt})_{40}\right]$, is a potential minor impurity in solid 5. The presence of the $\mathrm{Mn}^{\mathrm{III}}$ ion results in the introduction of an unoccupied $\mathrm{Mn}$ d-based alpha-state within the band gap. There is therefore the possibility of an allowed valence band $(\mathrm{p}-\mathrm{O}) \rightarrow$ metal $(\mathrm{d}-\mathrm{Mn})$ charge transfer transition. Importantly, however, only the higherenergy band at $275 \mathrm{~nm}$ is observed in the UV-visible spectrum of a saturated solution of 5 in $\mathrm{EtOH}$, with no sign of the minor band at $375 \mathrm{~nm}$ (see ESI, section ESI-6†). This shows that the low-energy band is not in fact an intrinsic feature of the electronic structure of the cage but arises from an extrinsic impurity. Indeed, further experiments showed that during its synthesis, crystalline $\mathbf{5}$ is generated along with a finely-divided amorphous powder which it appears can never be fully separated from 5, despite repeated washing of the crystals with EtOH. Fig. 7 also shows the UV-visible spectrum of this amorphous material (blue trace). It is clear that the minor absorption at $375 \mathrm{~nm}$ in the UV-visible spectrum of 5 matches the spectrum of the impurity at its absorption edge exactly.

The insert to Fig. 7 (top right, red trace) shows the experimental determination of the band gap components of crystalline 5, as isolated from the reaction mixture and washed repeatedly with EtOH. There are two apparent band gap components which arise from 5 and the impurity phase; a higher band gap component of $3.56 \mathrm{eV}$ which is due to 5 and a lower band gap component of $2.69 \mathrm{eV}$ which is due to the impurity. 
Our assignment of the higher band gap component to $\mathbf{5}$ is also consistent with DOS (Density of States) calculations which show that the band structures of $\mathbf{1}$ and $\mathbf{5}$ are similar (see section 3 of this paper). The presence of a common impurity provides a plausible explanation for the underestimation of the band gap of $\mathbf{1}(2.65 \mathrm{eV})^{8 a}$ and, by implication, of the recently reported cage $\left[\mathrm{Ti}_{28} \mathrm{MnO}_{36}(\mathrm{OH})(\mathrm{OEt})_{40}\right](2.74 \mathrm{eV})$ which, as described previously in section 2.1 , has a very similar structure to 5 only with an $\mathrm{H}_{2} \mathrm{O}$ molecule replacing $\mathrm{K}^{+}{ }^{8 c}$

No direct information on the composition of the impurity present in $\mathbf{5}$ could be obtained from powder XRD analysis since it is amorphous (see ESI, section ESI-6†). However, it probably contains a range of inorganic and residual organic components. One likely impurity in $\mathrm{Mn}^{\mathrm{II}}$-doped POT cages (like $\mathbf{1}$ and 5) is $\mathrm{Mn}$-doped $\mathrm{TiO}_{2}$, which has an almost identical literature band gap of $2.73 \mathrm{eV}$ (for $0.06 \mathrm{wt} \%$ loading of $\mathrm{Mn}$ ). ${ }^{9,21}$ The presence of amorphous $\mathrm{TiO}_{2}$ as a contaminant in $\mathbf{1}$ or 5 would not be surprising given that water of crystallisation is present in the $\mathrm{Mn}(\mathrm{AcO})_{3} \cdot 2 \mathrm{H}_{2} \mathrm{O}$ starting material, which would react readily with $\mathrm{Ti}(\mathrm{OEt})_{4}$ to give $\mathrm{TiO}_{2}$. Support for this proposition is provided by a study of the deliberate hydrolysis of the previously described cage 1 using a 50 : 50 EtOH- $\mathrm{H}_{2} \mathrm{O}$ solution, followed by sonication and final calcination of the solids produced at $400{ }^{\circ} \mathrm{C}$ to remove any organic residues. The material produced shows a significant reduction in the band gap compared to the original cage, with the direct analysis of the absorption edge giving a band gap of $2.69 \mathrm{eV}$ (ESI, section ESI-7.1†). ${ }^{22}$ Powder XRD on this material shows that it contains $\mathrm{TiO}_{2}$ in the anatase phase (Fig. ESI-7.2†) and EDS analysis indicates a ratio of $\mathrm{Mn}: \mathrm{Ti}$ of $c a$. 6.2:100. This value of (a)

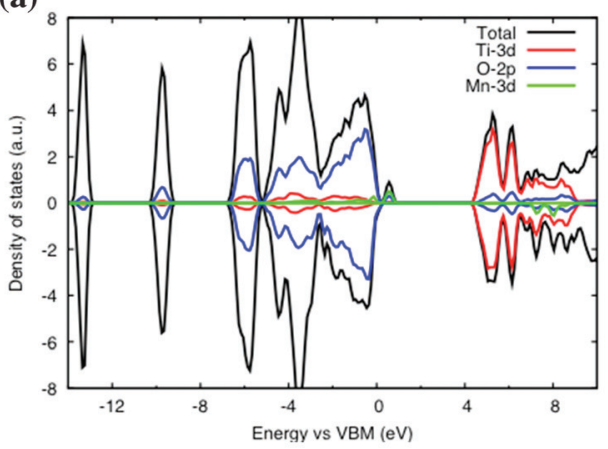

(c)

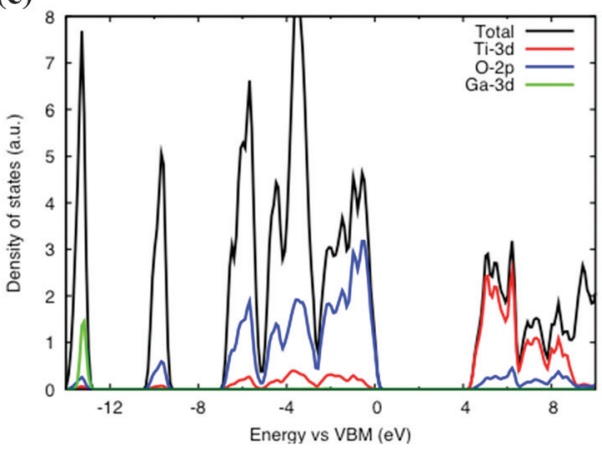

(b)

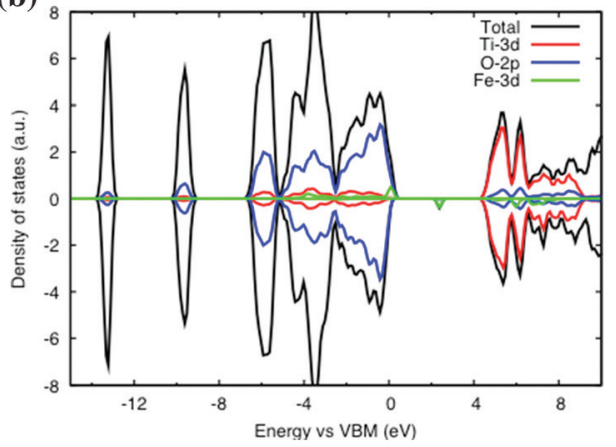

(d)

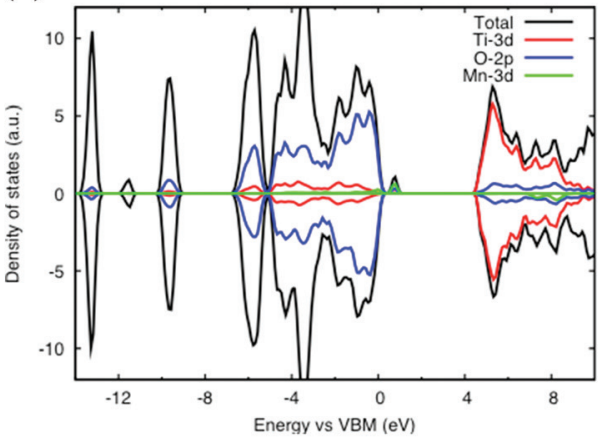

(e)

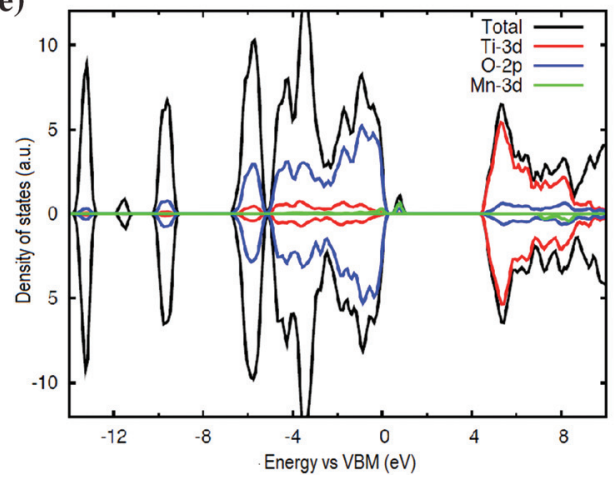

Fig. 8 Plots of projected density of states calculated using the B3LYP functional. (a) 1 , (d) 2, (c) 3, (d) the $\mathrm{Ti}_{28}$ component of 5, and (e) the Ti 27 component of 5. The energy is referenced to the valence band maximum (VBM) of the cages. Spin-up and spin-down channels are distinguished by the positive and negative signs of the density of states. 
the band gap is close to the band gaps previously reported for $\mathbf{1}^{8 a}(2.65 \mathrm{eV})$ and the recently reported cage $\left[\mathrm{Ti}_{28} \mathrm{MnO}_{36}(\mathrm{OH})\right.$ $\left.(\mathrm{OEt})_{40}\right](2.74 \mathrm{eV}),{ }^{8 c}$ and similar to the impurity in $5(2.69 \mathrm{eV})$.

\section{Theoretical calculations}

Electronic band structures of the cages 1, 2 and 3, and both the major $\mathrm{Ti}_{28}$ and minor $\mathrm{Ti}_{27}$ components of $\mathbf{5}$ have been calculated using density functional theory (DFT). Although the Kohn-Sham eigenstates are at best a first approximation to one-particle energy levels and the calculated band gaps should therefore not be taken literally, they are often informative in providing qualitative understanding of the electronic structures of materials and of the trend in the band gaps. The projected density of states (DOS) of the cages calculated by the hybrid functional B3LYP using a double- $\zeta$ basis functions with one set of polarization functions (DZVP) are shown in Fig. 8. The PBE functional has also been used, and we find that it gives similar projected DOS except for the expected smaller band gaps.

Cages 1, 2 and 3 are isomorphic with different dopant centres present. All three have very similar band gaps of about $4.5 \mathrm{eV}$, with the Ga cage 3 having a slightly larger band gap (in line with the experimental observations). This is due to the positions of $3 \mathrm{~d}$ orbitals of the central dopant metal ions. Both $\mathrm{Mn}^{\mathrm{II}}\left(\mathrm{d}^{5}\right)$ and $\mathrm{Fe}^{\mathrm{II}}\left(\mathrm{d}^{6}\right)$ have partially occupied $3 \mathrm{~d}$ orbitals that mix with the valence bands of the TiO cages, producing energy levels near the valence band maximum (VBM), i.e., the green peaks in the spin-up channel in Fig. 8(a) and (b). This leads to a small reduction in the band gaps. In contrast, the full-shell $\mathrm{d}^{10}$ configuration of $\mathrm{Ga}^{\mathrm{III}}$ has a much lower energy level [see the green trace in Fig. 9(c)] that does not affect the band gap since it does not mix with the valence band. The computed DOS of cage 1 is somewhat different from the work published previously in which a significantly smaller band gap of $\sim 2.5 \mathrm{eV}$ was calculated, using a B3LYP functional and 6-31G basis set (which was apparently consistent with the measured band gap of $2.65 \mathrm{eV}){ }^{8 a}$ We notice, however, that in this previously reported DOS plot there are some unoccupied alpha spin states projected onto Mn 3d orbitals, while the high-spin $\mathrm{Mn}^{2+}$ sextet should have fully occupied alpha $3 \mathrm{~d}$ states. Despite the larger size of the two cage components of $\mathbf{5}$ and the presence

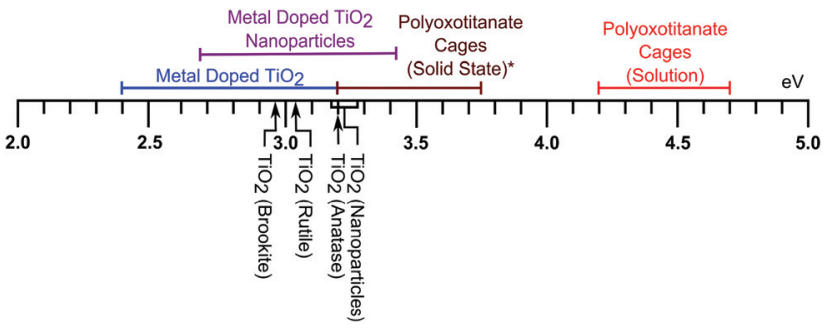

Fig. 9 Approximate ranges of the band gaps measured in this work (*) and in the literature for various classes of doped and undoped $\mathrm{TiO}_{2}$ and POT cages. of a $\mathrm{K}^{+}$ion, both cage components have very similar electronic structures to cage 1, as shown in Fig. 8(d) and (e).

Overall, the DOS calculations provide qualitative support for trend in the experimental band gap measurements and for the conclusion that all of the cages examined have similar band gaps.

\section{Conclusions}

We have shown that the interstitial cage arrangement originally found for the $\mathrm{Mn}^{\mathrm{II}}$ POT 1 can also support $\mathrm{Fe}^{\mathrm{II}}$ and $\mathrm{Ga}^{\mathrm{III}}$ ions at its centre, as illustrated by the formation of 2 and 3 . The trivalent cation of $\mathbf{3}$ is accommodated within the neutral cage arrangement by incorporating one instead of two $\mathrm{OH}$ groups in the host POT framework. The formation of an essentially isostructural series of cages which contain different dopant metal ions allows comparison of their optical properties, in the absence of major structural changes in the cage architecture. We conclude from band gap determinations that 1 does not have the very low band gap that has been reported of $2.65 \mathrm{eV}$ but a much higher band gap of $3.38 \mathrm{eV}$. In addition, the replacement of $\mathrm{Mn}^{\mathrm{II}}$ by $\mathrm{Fe}^{\mathrm{II}}$ has no effect on the bandgap, while replacement with $\mathrm{Ga}^{\mathrm{III}}$ results in a small increase.

Based on the current results and on the measured band gaps of metal-doped bulk $\mathrm{TiO}_{2}$, metal-doped $\mathrm{TiO}_{2}$ nanoparticles, and un-doped and metal-doped POT cages reported in the literature, a bar graph of the ranges of each class of material can be drawn (Fig. 9). ${ }^{23}$ We conclude that the range of values we are observing for metal-doped POT cages in the solid state is higher than that found for bulk metal-doped $\mathrm{TiO}_{2}$ but overlaps with metal-doped $\mathrm{TiO}_{2}$ nano-particles. It can be noted that the relative magnitudes of these band gaps makes intuitive sense in respect to the size regimes of the $\mathrm{Ti}_{x} \mathrm{O}_{y}$ cores involved (i.e., ca. 5-20 $\mathrm{nm}$ for nanoparticles, ca. 0.5-1.0 $\mathrm{nm}$ for POT cages).

Finally, our findings emphasise that great care should be taken in the measurement of the optical properties of metaldoped POT cages because of a combination of their hydrolytic sensitivity, ${ }^{7 f}$ the fact that they are often formed together with other byproduct cages, ${ }^{7 f, 33}$ and because of the potential presence of metal-doped $\mathrm{TiO}_{2}$ as a low band gap contaminant. ${ }^{7 f}$

\section{Experimental section}

\subsection{Synthesis of 2,3 and 4}

Autoclaves were charged with reactants under $\mathrm{N}_{2}$ in a glove box. Although the crystalline products were isolated and manually separated from impurities in air, they were then stored under $\mathrm{N}_{2}$ in a glove box (Saffron type $\alpha$ ). Ethanol was dried by distillation over $\mathrm{Mg}$. All chemicals were acquired from the Sigma-Aldrich Corporation.

5.1.1. Synthesis of 2. Titanium ethoxide $(7.00 \mathrm{ml}$, $33.4 \mathrm{mmol})$, iron(II) sulfate heptahydrate $(278.0 \mathrm{mg}, 1.0 \mathrm{mmol})$ and anhydrous ethanol $(7.00 \mathrm{ml}, 120 \mathrm{mmol})$ were placed in a 
Table 1 Details of the data collections and refinements of 2, 3, 4 and 5

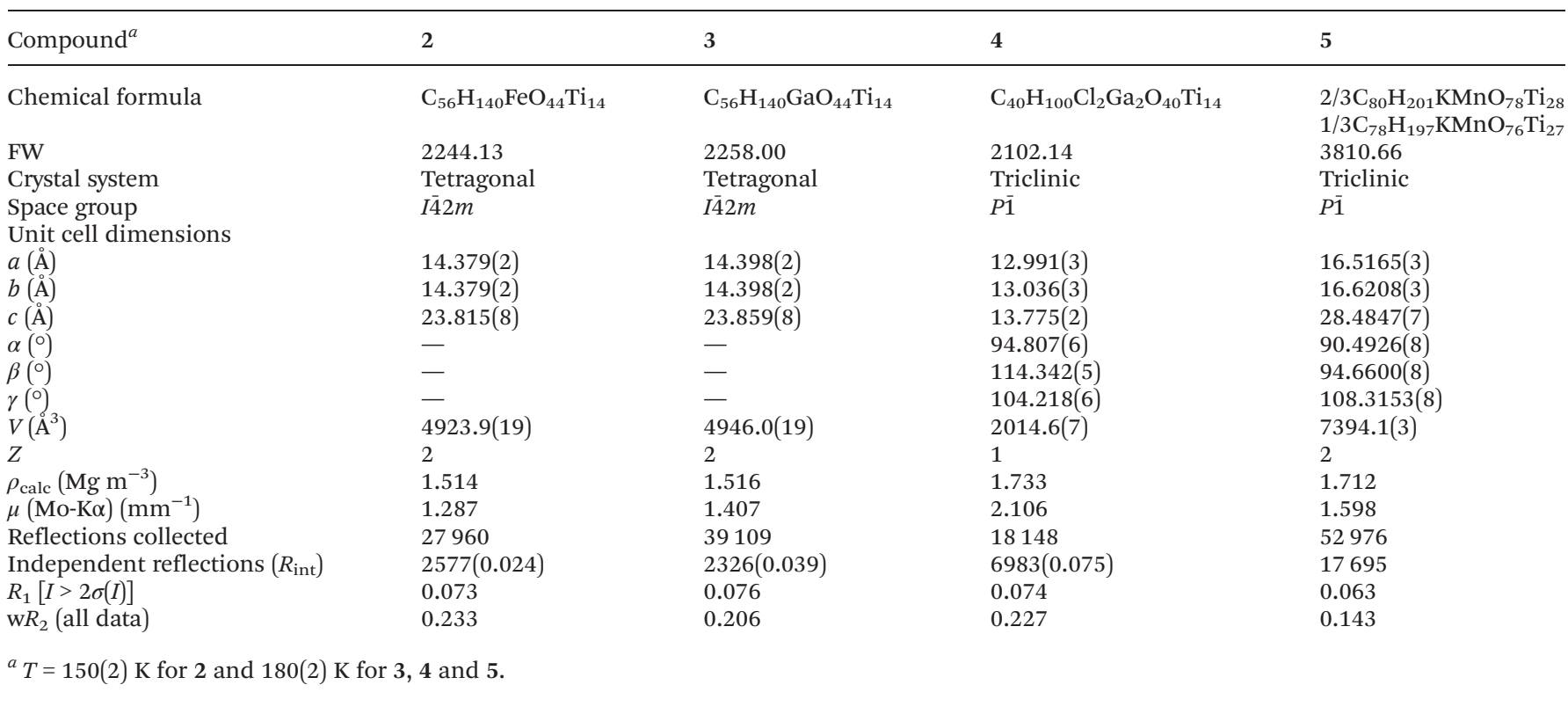

teflon-lined autoclave and heated at $150{ }^{\circ} \mathrm{C}$ for 72 hours. Cooling at $1{ }^{\circ} \mathrm{C}$ per minute to room temperature gave blockshaped colorless crystals of $2(0.23 \mathrm{~g} ; 10 \%$ yield, with respect to $\mathrm{FeSO}_{4} \cdot 7 \mathrm{H}_{2} \mathrm{O}$ supplied). IR $\left(4000-650 \mathrm{~cm}^{-1}\right): 3372(\mathrm{w})(\mathrm{O}-\mathrm{H}$ str.), 2924(w), 2860(w), 1642(w), 1445(w), 1376(w), 1125(s), 1074(m), 896(w), 807(m), 666(s). Elemental analysis (\%) calcd for $\mathrm{C}_{56} \mathrm{H}_{142} \mathrm{FeO}_{44} \mathrm{Ti}_{14}$ : C 30.0, H 6.4; found C 30.0, H 6.2.

5.1.2. Synthesis of 3. Titanium ethoxide $(7.00 \mathrm{ml}$, $33.4 \mathrm{mmol}$ ), anhydrous gallium(III) chloride (281.3 mg, $1.0 \mathrm{mmol})$ and anhydrous ethanol $(7.00 \mathrm{ml}, 120 \mathrm{mmol})$ were placed in a teflon-lined autoclave and heated at $150{ }^{\circ} \mathrm{C}$ for 72 hours. Cooling at $1^{\circ} \mathrm{C}$ per minute to room temperature gave block-shaped colourless crystals of $2(0.08 \mathrm{~g} ; 3.5 \%$ yield, with respect to $\mathrm{GaCl}_{3}$ supplied). IR (4000-650 cm $\left.\mathrm{cm}^{-1}\right): 3341$ (ws) (O-H str.), 2977(w), 2922(w), 2868(w), 1636(w), 1495(w), 1377(w), 1122 (vs), 1075(vs), 1015(m), 813(s), 665(s). Elemental analysis (\%) calcd for $\mathrm{C}_{56} \mathrm{H}_{141} \mathrm{GaO}_{44} \mathrm{Ti}_{14}$ : C 29.8, H 6.2; found C 29.8, H 6.2.

5.1.3. Synthesis of 5. Titanium ethoxide $(1.00 \mathrm{ml}$, $4.8 \mathrm{mmol})$, manganese(III) acetate dihydrate $(0.07 \mathrm{~g}$, $0.25 \mathrm{mmol})$, potassium acetate $(0.01 \mathrm{~g}, 0.10 \mathrm{mmol})$ and anhydrous ethanol $(5.00 \mathrm{ml}, 86 \mathrm{mmol})$ were placed in a teflon-lined autoclave and heated at $150{ }^{\circ} \mathrm{C}$ for 72 hours. Cooling at $10{ }^{\circ} \mathrm{C}$ per hour to room temperature gave colourless crystals of $\mathbf{5}$ which were separated from a finely-divided yellow byproduct by repeated washing with dry EtOH (final yield of $\mathbf{5}$ $0.09 \mathrm{~g} ; 23 \%$ yield, with respect to KAcO supplied). IR (4000-650 cm $\mathrm{cm}^{-1}$ ): 3337(ws) (O-H str.), 2967(w), 2921(w), 2857w), 1439(w), 1373(m), 1353(w), 1128(vs), 1070(s), 919(m), 813(w), 758(s), 675(s). Elemental analysis (\%) calcd for $\mathrm{C}_{78} \mathrm{H}_{195} \mathrm{KMnO}_{77} \mathrm{Ti}_{27.50}$ : C 25.0, H 5.2; found C 24.6, H 5.3.

\subsection{Crystallographic studies}

Data were collected on a Nonius Kappa CCD diffractometer using $\operatorname{Mo}\left(K_{\alpha}\right)$ radiation $(\lambda=0.71073 \AA)$. The structures were solved and refined by full matrix least-squares on $F^{2}$ using SHELXTL programme. ${ }^{24}$ All atoms with the exception of $\mathrm{C}$ and $\mathrm{H}$ were refined anisotropically. All four structures contain disordered ethyl groups. Ethyl groups were treated with similardistance (SAME) and similar U-restraints (SIMU). Disordered groups were split over two positions and refined with occupancy factors. The reflection data of $\mathbf{5}$ were truncated at $2 \theta=$ $45^{\circ}$ due to the lower resolution of the weakly diffracting crystals. CCDC reference numbers CCDC 984451, 984452, 984453 and 984454 for 2, 3, 4 and 5, respectively (Table 1).

\subsection{Theoretical calculations}

DFT calculations were carried out using the freely-available program CP2 K/Quickstep. ${ }^{25,26}$ The $2 \mathrm{~s}$, 2 p electrons of the C and $\mathrm{O}$ atoms, 3s, 3p, 3d, 4s electrons of the Ti, Mn and Fe atoms, the $3 \mathrm{~d}, 4 \mathrm{~s}, 4 \mathrm{p}$ electrons of the $\mathrm{Ga}$ atom, and $3 \mathrm{~s}, 3 \mathrm{p}, 4 \mathrm{~s}$ electrons of the $\mathrm{K}$ atom were treated as valence electrons. The basis sets are double- $\zeta$ basis functions with one set of polarization functions (DZVP). The plane wave cutoff for density expansion in reciprocal space was $280 \mathrm{Ry}$. The core electrons were represented by analytic Goedecker-Teter-Hutter (GTH) pseudopotentials. ${ }^{27,28}$ For the hybrid B3LYP functional, the density matrix was re-expanded in a small auxiliary basis set leading to massive speedup of the calculation of Hartree-Fock exchange (HFX), and a truncated Coulomb operator was used to compute exchange integrals. ${ }^{29}$ The convergence criterion for wave function optimization was set by a maximum electronic gradient of $3 \times 10^{-7}$ and an energy difference tolerance between self-consistent field (SCF) cycles of $10^{-13}$. The geometry of each of the cages 1-4 was optimized using the BFGS minimizer. These settings have been used in previous publications to simulate the $\mathrm{TiO}_{2}$ and POT cages with a good accuracy. ${ }^{30-33}$ Unrestricted Kohn-Sham formalism was used for the spin polarized cages $\mathbf{1}, 2$ and $\mathbf{4}$, while for the closed 
shell cage 3 restricted Kohn-Sham was employed. Both $\mathrm{Mn}^{\mathrm{II}}$ and $\mathrm{Fe}^{\mathrm{II}}$ are in the high spin state, i.e., sextet and quintet, respectively.

\section{Acknowledgements}

We thank The China Scholarship Council (Y.L.), The EPSRC (T.C.K., P.M., A.S.), The EU (Advanced Investigator award ERC grant for D.S.W.) and The NSFC 21273163 (L.G.), The Christian Doppler Research Association and the OMV Group (J.W.) for financial support. We also thank the Spanish Ministerio de Economia y Competitividad under grants ENE2011-24-412 and IPT-2011-1553-420000 and the XPS Service of Instituto de Ciencias de Materiales de Sevilla for technical and scientific support. We also thank Dr J. E. Davies (Cambridge) for collecting X-ray data on 3, 4 and 5, Dr D. A. Jefferson for TEM and EDX studies, and Dr Erwin Reisner for the use of a UV-visible spectrometer.

\section{Notes and references}

1 A. Fujishima and K. Honda, Nature, 1972, 238, 37; M. Ashokkumar, Int. J. Hydrogen Energy, 1998, 23, 427; M. Ni, M. K. H. Leung, D. Y. C. Leung and K. Sumathy, Renewable Sustainable Energy Rev., 2007, 11, 401; X. Chen and S. S. Mao, Chem. Rev., 2007, 107, 2891.

2 R. Asahi, T. Ohwaki, K. Aoki and Y. Taga, Science, 2001, 293, 269.

3 H. Weng, X. Yang, J. Dong, H. Miuseki, M. Kawasaki and Y. Kawazoe, Phys. Rev. B: Condens. Matter, 2004, 69, 125219.

4 See also: A. Zaleska, Recent Pat. Eng., 2008, 2, 157.

5 For recent publications involving DFT calculations of Mn, $\mathrm{Fe}$ and $\mathrm{Ga}$ relevant to the current work, see: G. Shao, J. Phys. Chem. C, 2009, 113, 6800; A. Iwaszuk and M. Nolan, J. Phys.: Condens. Matter, 2011, 23, 334207; W. Körner and C. Elsässer, Phys. Rev. B: Condens. Matter, 2011, 83, 205315; C. Lee and C. M. Aitkins, J. Phys. Chem. C, 2009, 113, 6800.

6 S. Lany and A. Zunger, Model. Simul. Mater. Sci. Eng., 2009, 17, 084002; B. J. Morgan and G. W. Watson, Phys. Rev. B: Condens. Matter, 2009, 80, 233102; C. Lee and C. M. Aikens, Comput. Theor. Chem., 2013, 1013, 32.

7 (a) S. Eslava, F. Hengesbach, M. McPartlin and D. S. Wright, Chem. Commun., 2010, 46, 4701; (b) S. Eslava, M. McPartlin, R. L. Thomson, J. M. Rawson and D. S. Wright, Inorg. Chem., 2010, 49, 11532; (c) S. Eslava, B. P. R. Goodwill, M. McPartlin and D. S. Wright, Inorg. Chem., 2011, 50, 5655; (d) Y. Lv, J. Willkomm, A. Steiner, L. Gan, E. Reisner and D. S. Wright, Chem. Sci., 2012, 3, 2470; (e) Y. Lv, J. Willkomm, M. Leskes, A. Steiner, T. C. King, L. Gan, E. Reisner, P. T. Wood and D. S. Wright, Chem. - Eur. J., 2012, 18, 11867; $(f)$ Y. Lv, M. Yao, J. P. Holgado, T. Roth, A. Steiner, L. Gan and
R. M. Lambert, $R S C$ Adv., 2013, 3, 13659; (g) Y.-H. Lai, T. C. King, D. S. Wright and E. Reisner, Chem. - Eur. J., 2013, 19, 12943; (h) Y.-H. Lai, C.-Y. Lin, Y. Lv, T. C. King, A. Steiner, N. M. Muresan, L. Gan, D. S. Wright and E. Reisner, Chem. Commun., 2013, 49, 4331.

8 (a) Y. Chen, J. Sokolow, E. Trzop, Y.-S. Chen and P. Coppens, J. Chin. Chem. Soc., 2013, 60, 887; (b) Y. Chen, J. D. Sokolow, G. Trzop and P. Coppens, Dalton Trans., 2013, 42, 15285; (c) Y. Chen, E. Trzop, A. Makal, Y.-S. Chen and P. Coppens, Dalton Trans., 2014, 43, 3839.

9 L. G. Devi, N. Kottam and S. G. Kumar, J. Phys. Chem. C, 2009, 113, 15593.

10 R. Schmid, A. Mosset and J. Galy, The byproduct is largely the monoclinic form, as shown by later powder and singlecrystal XRD studies, Dalton Trans., 1991, 1999.

11 E. I. Heiba, R. M. Dessau and W. J. Koehl Jr., J. Am. Chem. Soc., 1969, 91, 138.

12 W. H. Baur, Acta Crystallogr., Sect. A: Cryst. Phys., Diffr., Theor. Gen. Crystallogr., 1961, 14, 214; W. H. Bauer and A. A. Khan, Acta Crystallogr., Sect. B: Struct. Crystallogr. Cryst. Chem., 1971, 27, 2133; M. Horn, C. F. Schweryfeger and E. P. Meagher, Z. Kristallogr., 1972, 136, 272.

13 I. D. Brown, The Chemical Bond in Inorganic Chemistry, The Bond Valence Model, Oxford, 2002; http://www.iucr.org/ resources/data/datasets/bond-valence-parameters.

14 J. E. Huheey, Inorganic Chemistry, Principles of Structure and Reactivity, Harper, 3rd edn, 1983, p. 73.

15 B. R. McGarvey, M. J. Taylor and D. G. Tuck, Inorg. Chem., 1981, 20, 2010; Z. Cerny, J. Machacek, J. Fusek, O. Kriz, B. Casensky and D. G. Tuck, J. Organomet. Chem., 1993, 456, 25.

16 Search of the Cambridge Crystallographic Data Base, August 2013.

17 Y. Chen, E. Trzop, A. Makal, J. D. Sokolow and P. Coppens, Inorg. Chem., 2013, 52, 4750.

18 R. A. Smith, Semiconductors, Cambridge University Press, Cambridge, 2nd edn, 1978.

19 C. L. Luu, Q. T. Nguyen and S. T. Ho, Adv. Nat. Sci.: Nanosci. Nanotechnol., 2010, 1, 015008.

20 Ga-doping has also be shown to result in a small band gap reduction of $\mathrm{TiO}_{2}$, see for example: A. N. Banergee, S. W. Joo and B.-K. Min, J. Nanomater., 2012, 201492.

21 It is also possible that higher oxidation state oxides, $\mathrm{MnO}_{x}$, are present, particularly bearing in mind the broad absorption exhibited by the impurity across the visible region, see: Q. Jin, H. Arimoto, M. Fujishima and H. Tada, Catalysts, 2013, 3, 444; V. V. Papadimitriou, V. G. Stefanopoulos, M. N. Romanias, P. Papagiannakopoulos, K. Sambani, V. Tudose and G. Kiriakidis, Thin Solid Films, 2011, 520, 1195.

22 For comparison, the band gap for hydrolysed 2 is $2.84 \mathrm{eV}$ using the onset method (Fig. ESI-7.1†). Again this sample contains $\mathrm{TiO}_{2}$ in the anatase phase (Fig. ESI-7.2†). EDS analysis indicates a ratio of $\mathrm{Fe}: \mathrm{Ti}$ of $c a$. $6.9: 100$.

23 P. D. Matthews, T. C. King and D. S. Wright, manuscript in preparation. 
24 G. M. Sheldrick, Acta Crystallogr., 2008, 64, 112.

25 J. VandeVondele, M. Krack, F. Mohamed, M. Parrinello, M. Chassaing and J. Hutter, Comput. Phys. Commun., 2005, 167, 103.

26 The CP2 K developers group website: http://www.cp2k. org/.

27 S. Goedecker, M. Teter and J. Hutter, Phys. Rev. B: Condens. Matter, 1996, 54, 1703.

28 C. Hartwigsen, S. Goedecker and J. Hutter, Phys. Rev. B, 1998, 58, 3641.
29 M. Guidon, J. Hutter and J. VandeVondele, J. Chem. Theor. Comput., 2010, 6, 2348.

30 J. Cheng, M. Sulpizi, J. VandeVondele and M. Sprik, ChemCatChem, 2012, 4, 636.

31 J. Cheng and M. Sprik, Phys. Rev. B: Condens. Matter, 2012, 82, 081406.

32 J. Cheng and M. Sprik, J. Chem. Theor. Comput., 2010, 6, 880-889.

33 Y. Lv, J. Cheng, A. Steiner, L. Gan and D. S. Wrigh, Angew. Chem., Int. Ed., 2014, 53, 1934. 